\title{
CERTIFICAÇÃO FLORESTAL: INSTRUMENTO PARA A SUSTENTABILIDADE
}

\author{
Thais Muniz Ottoni Santiago'
}

\section{Sarita Soraia de Alcântara Laudardes ${ }^{2}$}

\section{José Luiz Pereira de Rezende ${ }^{3}$}

RESUMO: A certificação florestal parece ser um instrumento capaz de incentivar o manejo florestal sustentável e a sua consolidação e disseminação podem se valer muito de estudos que investiguem seus fundamentos e esclareçam a sua aplicação. Diante disso, realizou-se uma pesquisa básica e exploratória, delineada por métodos de pesquisa bibliográfica e documental, com o objetivo de analisar a implementação do principal selo de certificação florestal do mundo, o FSC - Forest Stewardship Council. Os objetivos específicos desse estudo foram: elucidar a criação desse selo, buscando identificar a sua finalidade e o contexto social da época; analisar as principais características do processo; os seus principais custos e benefícios; e apresentar um panorama mundial da sua aplicação. Os resultados mostraram que a certificação FSC surgiu como uma das mais significativas inciativas a favor da sustentabilidade do setor florestal, em um momento em que a cooperação internacional foi convocada para a melhoria da qualidade ambiental. O processo de certificação é voluntário e baseado em princípios e critérios que mantêm padrões de desempenho ambiental, social e econômico para as operações de manejo em diferentes sistemas florestais do mundo. Ele gera custos indiretos e diretos, sendo os últimos mais onerosos. Os benefícios são amplos, do

\footnotetext{
${ }_{1}^{1}$ Doutoranda em Eng. Florestal, Universidade Federal de Lavras. thaismottoni@gmail.com

2 Mestranda em Eng. Florestal, Universidade Federal de Lavras. saritalaudardes@gmail.com

${ }^{3}$ Professor do Departamento de Ciências Florestais, Universidade Federal de Lavras. jlprezen@dcf.ufla.br
} 
ponto de vista econômico, social e ambiental e atingem segmentos diversos da sociedade. O selo está presente em diversos países, com 10\% das florestas manejadas no mundo certificadas. Concluiu-se que a certificação FSC desempenha um papel importante na busca pela sustentabilidade do setor florestal e deve ser incentivada.

Palavras-chave: Manejo florestal. Cadeia de custódia. Selo FSC.

\section{INTRODUÇÃO}

Produtos florestais madeireiros e não madeireiros foram, são e, aparentemente sempre serão, parte expressiva da base da economia nos níveis local e global. A história mostra que formas de exploração predatória têm sido a regra na utilização de praticamente todos os ecossistemas florestais e em escala mundial (BORGES, 2005). No entanto, diante da possibilidade de esgotamento de recursos naturais e da ameaça à qualidade da vida humana, surge, a partir da década de 1970, uma demanda global pela substituição desse modelo irracional de exploração por outro que promova a sustentabilidade do desenvolvimento.

Como consequência dessa busca, o manejo de florestas vem passando por um acelerado processo de transformação: no campo tecnológico, com a introdução de novas práticas de manejo; no campo gerencial, com a introdução de novos sistemas de manejo e no campo estratégico, com novos instrumentos de políticas públicas e de relação com o mercado (GUÉRON, 2003). Essas mudanças indicam um cenário promissor para o manejo florestal como instrumento de promoção do desenvolvimento sustentável, pois além de assegurar o equilíbrio ecológico e a capacidade de regeneração das florestas, pressupõe viabilidade econômica e justiça social.

É nesse contexto que está inserida a certificação florestal. Seu objetivo principal é provar ao consumidor que determinado produto é derivado de uma floresta bem manejada ou que sua cadeia de custódia é baseada nos princípios da sustentabilidade. Isso se faz visível pelo rótulo apropriado no produto ou em sua embalagem. A pressão exercida pelo 
poder público e a crescente conscientização ambiental do consumidor, que procura atestar a procedência da mercadoria que será adquirida, aumentam significativamente a importância e a demanda pela certificação florestal.

Considerando o papel da certificação na busca pela sustentabilidade, o presente trabalho teve o objetivo de analisar o selo de certificação florestal mais disseminado no mundo, o FSC (Forest Stewardship Council), visando ao seu fortalecimento conceitual e à sua disseminação. Os objetivos específicos foram: elucidar a criação do selo FSC, abordando o contexto social da época; analisar as principais características do processo, identificar seus principais custos e benefícios; e apresentar um panorama mundial da certificação FSC.

Realizou-se uma pesquisa básica e exploratória, com o propósito de obter uma visão geral e aproximativa do objeto de estudo, com vistas à formulação de problemas mais precisos e hipóteses pesquisáveis em estudos posteriores. O delineamento do estudo seguiu métodos de pesquisa bibliográfica e documental em uma amostragem nãoprobabilística por acessibilidade, segundo o proposto por Gil (2010).

\section{A CERTIFICAÇÃO FSC}

\subsection{ANTECEDENTES E JUSTIFICATIVAS}

O modelo de exploração mundial baseado na idéia de meio ambiente como acessório do desenvolvimento (e não como parte intrínseca dele) começou a ser questionado na segunda metade do século XX (VIOLA, 1997; SOUSA, 2005). A Conferência de Estocolmo, em 1972, foi um marco histórico nessa mudança de paradigma. Ela reconheceu a urgência em proteger e melhorar a qualidade ambiental como uma condição ao bem-estar humano e à contínua disponibilidade de recursos naturais, promovendo a cooperação internacional para esse objetivo (UNITED..., 1972).

Nos anos 80, diante dessa nova perspectiva e sob o impacto das elevadas taxas de desmatamento da Amazônia, dos grandes incêndios florestais da Indonésia e dos impactos sociais da exploração florestal sobre populações tradicionais da Bacia do 
Congo, diversas ONGs européias e norte-americanas começaram a estruturar campanhas de boicote ao consumo de madeiras tropicais. A lógica era reduzir a demanda e, com isso, a pressão sobre as florestas tropicais. Também recrudesceram as campanhas contra o corte raso de grandes áreas de florestas temperadas e boreais, sobretudo no Canadá e noroeste dos EUA. Na Europa, especialmente na Escandinávia, onde a exploração predatória ameaçava a continuidade da produção e resultava em impactos sociais indesejáveis, também cresciam as pressões contra os sistemas convencionais de manejo florestal (VIANA ET AL., 2002).

A resposta da indústria florestal às pressões e movimentos de boicote foi a utilização de declarações e selos próprios, ou de entidades por elas controladas, atestando que os seus produtos eram "ecologicamente corretos", "respeitavam as populações indígenas", "promoviam a conservação da natureza”, etc. Um parcela expressiva dessas auto-declarações ou auto-certificações, no entanto, era completamente falsa e, quase a totalidade, não podia ser verificada de forma objetiva no campo (GUÉRON, 2003; VIANA ET AL., 2002).

No final da década de 1980, o movimento ambientalista começou a questionar a eficácia dos boicotes como alternativa para resolver o problema do desmatamento e empobrecimento das florestas naturais (QUEIROZ, 2003). O impacto da redução dos mercados para produtos florestais, com a consequente redução de preços e desvalorização econômica das florestas, passou a não fazer sentido diante da racionalidade econômica do desmatamento. Para o caso das florestas tropicais argumentava-se que o maior desafio era promover a valorização econômica da produção de florestas bem manejadas como forma de conter o processo de expansão da fronteira agrícola e transformar a atividade florestal num uso da terra atraente para os diferentes agentes sociais e econômicos do meio rural (BORGES, 2005).

No campo social, a morte de Chico Mendes, em 1988, deu caráter universal ao movimento dos seringueiros da Amazônia brasileira e deixou clara mensagem de que a conservação da floresta depende da manutenção e da construção da cidadania para os povos que nela vivem. Assim, construiu-se a ideia de que a floresta pode ser conservada com o uso apropriado de seus produtos, desde que submetida a boas práticas de manejo.

Ainda nesse período, surge na região da Nova Inglaterra, EUA, um movimento para certificar a madeira consumida por artesãos que tinham um forte compromisso com a 
conservação das florestas. Foi fruto desse movimento a WARP (Woodworkers Association for Rainforest Protection), uma associação de artesãos voltada para a proteção das florestas pluviais, que realizou diversos encontros para a discussão de um sistema de certificação de madeiras oriundas de florestas bem manejadas. Nasceu também desse movimento, o programa Smartwood da ONG Rainforest Alliance, que elaborou os primeiros padrões práticos para verificar se determinada floresta era bem manejada ou não (VIANA ET AL., 2002). Em outros países e especialmente na Inglaterra, a WWF iniciou um diálogo com importadores e consumidores de madeiras tropicais para que esses retirassem os "autocertificados" e apoiassem a criação de um sistema de certificação universal, com critérios claros e capazes de serem auditados e monitorados por instituições independentes.

Concomitantemente, o Relatório de Bruntland (1991) redefine a pauta da política ambiental internacional e define o conceito de desenvolvimento sustentável, que anos depois, tornou-se compromisso de quase todos os países participantes da Eco-92. Sob o impacto do conceito de "desenvolvimento sustentável", o manejo florestal passa considerar não só a capacidade de recolonização da população florestal explorada, mas também as dimensões sócio-culturais, ambientais e econômicas da produção. Isso implica uma visão mais ampla dos objetivos do manejo florestal, que passa a incluir a geração de serviços ambientais pelas florestas, a geração de benefícios sociais para os trabalhadores e as comunidades locais, e o respeito à cultura e direitos das populações afetadas.

Ainda na década de 90, uma das iniciativas mais significativas do mundo em prol do uso sustentável de florestas, ambientalistas, pesquisadores, engenheiros florestais, empresários da indústria e comércio de produtos de origem florestal, trabalhadores, outros povos da floresta e instituições certificadoras de 34 países reuniram-se em um conselho e realizaram consultas em diversos países, inclusive no Brasil, para captar informações sobre a oportunidade, viabilidade, riscos e estratégias para a criação de um sistema internacional de certificação (VIANA ET AL., 2002). Durante dois anos, eles buscaram definir o modo de auditar, em poucos dias, uma unidade de manejo florestal, avaliando o seu desempenho e incorporando as dimensões sócio-culturais, ambientais e econômicas. 
Em 1992, o FSC - Forest Stewardship Council - foi criado. Algumas instituições ambientalistas defendiam a não participação de empresas e empresários, com receio de perder o controle para estes em função do seu maior poder econômico. Representantes dos países do terceiro mundo receavam um controle absoluto das ONG's européias e norte-americanas. Ao final das negociações, nasceu o FSC como uma associação de membros, com uma participação minoritária de empresas (25\%) e uma paridade entre membros do "norte" e do "sul" nas suas estruturas decisórias.

O FSC foi criado como uma organização não-governamental independente e sem fins lucrativos, sediada em Bonn, na Alemanha, e integrada por representantes de organizações sociais, ambientalistas, do setor madeireiro e de produtos florestais, de povos indígenas, organizações comunitárias e certificadoras de produtos florestais de todo o mundo. Sua missão é desenvolver princípios e critérios universais de bom manejo florestal direcionados para a certificação; apoiar e ratificar o desenvolvimento de padrões nacionais e regionais de manejo florestal, harmonizados para determinados biomas; credenciar e monitorar organizações certificadoras independentes (ele não certifica, e sim, credencia certificadoras).

\subsection{PRINCÍPIOS E CRITÉRIOS DO FSC}

Para promover o manejo das florestas do mundo de forma ambientalmente adequada, socialmente benéfica e economicamente viável, o FSC estabelece um padrão mundial de 10 princípios (Quadro 1) e 56 critérios de manejo florestal que devem ser incorporados aos sistemas de avaliação e padrões de todas as organizações certificadoras que procurem o credenciamento junto ao FSC (CERTIFICAÇÃO..., 2011).

Princípios FSC

\begin{tabular}{|c|l|}
\hline \multicolumn{2}{|c|}{ Princípios FSC } \\
$\begin{array}{c}\text { Obediência às Leis e aos Princípios do } \\
\text { FSC }\end{array}$ & $\begin{array}{l}\text { O manejo florestal deve respeitar todas as leis aplicáveis } \\
\text { ao país onde opera, inclusive os tratados internacionais e } \\
\text { acordos assinados por este país, e obedecer a todos os } \\
\text { Princípios e Critérios do FSC. }\end{array}$ \\
\hline $\begin{array}{c}\text { Responsabilidades e direitos de posse e } \\
\text { uso da terra }\end{array}$ & $\begin{array}{l}\text { Os direitos de posse e uso de longo prazo relativos à terra } \\
\text { e aos recursos florestais devem ser claramente definidos, } \\
\text { documentados e legalmente estabelecidos }\end{array}$ \\
\hline Direitos dos Povos Indígenas & Os direitos legais dos povos indígenas de possuir, usar e \\
\hline
\end{tabular}




\begin{tabular}{|c|c|}
\hline & $\begin{array}{l}\text { manejar suas terras, territórios e recursos devem ser } \\
\text { reconhecidos e respeitados }\end{array}$ \\
\hline $\begin{array}{l}\text { Relações Comunitárias e Direitos dos } \\
\text { Trabalhadores }\end{array}$ & $\begin{array}{l}\text { As atividades de manejo florestal devem manter ou ampliar } \\
\text { o bem estar econômico e social de longo prazo dos } \\
\text { trabalhadores florestais e das comunidades locais }\end{array}$ \\
\hline Benefício da floresta & $\begin{array}{l}\text { As operações de manejo florestal devem incentivar o uso } \\
\text { eficiente dos múltiplos produtos e serviços da floresta para } \\
\text { assegurar a viabilidade econômica e uma grande gama de } \\
\text { benefícios ambientais e sociais }\end{array}$ \\
\hline Impacto Ambiental & $\begin{array}{l}\text { O manejo florestal deve conservar a diversidade ecológica, } \\
\text { os recursos hídricos, os solos, e os ecossistemas e } \\
\text { paisagens frágeis e singulares, e ao assim atuar, manter as } \\
\text { funções ecológicas e a integridade da floresta. }\end{array}$ \\
\hline Plano de Manejo & $\begin{array}{l}\text { Um plano de manejo - apropriado à escala e intensidade } \\
\text { das operações propostas - deve ser escrito, implementado } \\
\text { e atualizado. Os objetivos de longo prazo do manejo } \\
\text { florestal e os meios para atingi-los devem ser claramente } \\
\text { definidos. }\end{array}$ \\
\hline Monitoramento e Avaliação & $\begin{array}{l}\text { O monitoramento deve ser conduzido - apropriado à escala } \\
\text { e à intensidade do manejo florestal - para que sejam } \\
\text { avaliados a condição da floresta, o rendimento dos } \\
\text { produtos florestais, a cadeia de custódia, as atividades de } \\
\text { manejo e seus impactos ambientais e sociais. }\end{array}$ \\
\hline $\begin{array}{l}\text { Manutenção de florestas de alto valor de } \\
\text { conservação }\end{array}$ & $\begin{array}{l}\text { As atividades em manejo de florestas de alto valor de } \\
\text { conservação devem manter ou ampliar os atributos que } \\
\text { definem estas florestas. Decisões relacionadas às florestas } \\
\text { de alto valor de conservação devem sempre ser } \\
\text { consideradas no contexto de uma abordagem precautória. }\end{array}$ \\
\hline Plantações & $\begin{array}{l}\text { As plantações devem ser planejadas e manejadas de } \\
\text { acordo com os Princípios e Critérios anteriores. }\end{array}$ \\
\hline
\end{tabular}

Quadro 1. Princípios de Manejo Florestal da FSC

Os Princípios e Critérios da certificação são aplicáveis a todos os tipos de florestas (tropicais, boreais e temperadas) e tipos de manejo (nativas ou plantações). Eles funcionam como diretrizes para a elaboração de padrões nacionais ou regionais adaptados a determinado tipo de floresta e às diferentes realidades de manejo florestal, que por sua vez, são utilizados pelos certificadores nacionais.

No Brasil, o FSC começou suas atividades em 1994, por meio do Grupo de Trabalho FSC - Br, sob a coordenação do WWF-Brasil. Atualmente, quem representa o FSC no Brasil é o Conselho Brasileiro de Manejo Florestal (CBMF), criado em setembro de 2001, com o aval do FSC Internacional. Existem padrões brasileiros específicos para a Floresta Amazônica de Terra Firme e para Plantações e, desde 2008, existe um trabalho para a criação de padrões para outros tipos de floresta, como a de Várzea e a da Mata Atlântica, e também de manejo de espécies não-madeiráveis, como a castanha do Brasil, o palmito de açaí e a borracha (CERTIFICAÇÃO...,2011). 


\subsection{O PROCESSO DE CERTIFIAÇÃO FSC}

Existem dois tipos de certificação com o selo FSC (CERTIFICAÇÃO..., 2011): a certificação de Manejo Florestal, que é acessível a todos os produtores, de pequenas ou grandes operações ou associações comunitárias; e a certificação de Cadeia de Custódia, que se aplica aos produtores que processam a matéria prima de floresta certificada. As serrarias, os fabricantes e os designers que desejam utilizar o selo FSC no seu produto precisam obter o certificado para garantir a rastreabilidade que integra a cadeia produtiva desde a floresta até o produto final.

Assim, um produto final só pode estampar o selo FSC caso cada empresa envolvida em seu processamento tenha sido auditada e certificada por uma certificadora credenciada pelo FSC. Trata-se de um esforço conjunto - se um elo da cadeia faltar, não será possível garantir o selo no produto final. É por esta razão que não há uma quantidade ainda maior de produtos certificados no mercado. Embora exista um número significativo de empresas certificadas no país, elas nem sempre estão presentes em toda a cadeia produtiva de um produto.

A certificação é um processo voluntário constituído pelas etapas descritas no Quadro 2.

\begin{tabular}{|c|c|}
\hline Sequência & Etapa da Certificação \\
\hline 1 & $\begin{array}{l}\text { Depois da decisão em se certificar, pode ser solicitada junto a uma das certificadoras } \\
\text { credenciadas, uma pré-avaliação do manejo da floresta. Essa não é uma etapa obrigatória } \\
\text { do processo, mas uma consulta para verificar como aquela operação florestal está em } \\
\text { relação aos padrões de certificação referentes àquele tipo de manejo ou tipo de floresta; }\end{array}$ \\
\hline 2 & $\begin{array}{l}\text { A certificadora é contratada para fazer uma avaliação completa da área, com objetivo de } \\
\text { certificar a unidade de manejo. Ela define o escopo, a equipe de avaliação e as fases da } \\
\text { auditoria de campo. Antes da avaliação de campo, é realizado um processo de consulta } \\
\text { pública para que as certificadoras possam colher comentários das populações locais } \\
\text { acerca do manejo praticado pelo empreendimento; }\end{array}$ \\
\hline 3 & $\begin{array}{l}\mathrm{Na} \text { avaliação de campo, a equipe de auditores realiza uma visita às áreas de manejo e } \\
\text { verifica o cumprimento dos Princípios e Critérios do FSC; }\end{array}$ \\
\hline 4 & $\begin{array}{l}\text { A unidade de manejo florestal para ser certificada precisa necessariamente passar por } \\
\text { uma certificação de cadeia de custódia (CoC) na unidade de processamento ou } \\
\text { beneficiamento, o que irá garantir o rastreamento do produto desde o campo até sua } \\
\text { comercialização. Somente produtos explorados das unidades certificadas podem receber } \\
\text { o selo FSC; }\end{array}$ \\
\hline 5 & $\begin{array}{l}\text { Os auditores elaboram relatórios que constam as pré-condições (pontos que precisam ser } \\
\text { resolvidos antes do empreendimento receber a certificação) e condições (pontos que } \\
\text { podem ser resolvidos com o tempo) para o licenciamento da logomarca FSC, e ainda as }\end{array}$ \\
\hline
\end{tabular}




\begin{tabular}{|c|l|}
\hline & $\begin{array}{l}\text { recomendações (pontos da operação florestal que podem ser melhorados). Quando } \\
\text { existem pré-condições, a operação florestal tem um tempo para resolvê-las e convidar } \\
\text { novamente a certificadora para uma checagem final. Finalmente, o relatório final da } \\
\text { certificadora é analisado por especialistas e são tomadas as decisões para liberar ou não } \\
\text { a certificação; }\end{array}$ \\
\hline 6 & $\begin{array}{l}\text { A certificadora então elabora um resumo público sobre o processo de certificação da } \\
\text { operação florestal e disponibiliza o documento publicamente }\end{array}$ \\
\hline 7 & $\begin{array}{l}\text { Depois de certificada, a operação florestal recebe anualmente a visita da certificadora } \\
\text { responsável pelo licenciamento da logomarca FSC. Em casos de denúncia de } \\
\text { irregularidades, a certificadora poderá realizar visitas extras. Além disso, o certificado } \\
\text { FSC precisa ser renovado a cada } 5 \text { anos quando é realizado um outro processo de } \\
\text { avaliação completo; }\end{array}$ \\
\hline
\end{tabular}

Quadro 2. Etapas da certificação FSC

Para favorecer o envolvimento de grupos de interesse múltiplos, globais e locais, a realização de consultas públicas está prevista no FSC em dois momentos particulares: durante o processo de certificação da unidade de manejo florestal, para a coleta de informações sobre as práticas socioambientais e os impactos do empreendimento, e durante o desenvolvimento de padrões de certificação para que esses compreendam os as expectativas dos diversos grupos envolvidos na atividade florestal.

Em resumo, o processo de certificação FSC se dá pelo requerimento e proposta para certificação; pré-avaliação (opcional); consulta a lideranças locais/regionais; auditoria principal; relatório e revisão do processo; disponibilização de um resumo público referente à certificação; monitoramento anual e renovação da certificação em cinco anos.

\subsection{AS CERTIFICADORAS FSC NO BRASIL}

O FSC Internacional (FSC IC) estabelece regras para o credenciamento das certificadoras que serão as responsáveis pela liberação do selo FSC, sendo essas monitoradas constantemente. No Brasil existem atualmente onze certificadoras credenciadas pelo FSC IC: Apcer Brasil - Associação Portuguesa de Certificação, Bureau Veritas Certification, IMO - Instituto de Mercado Ecológico, Programa Smart Wood (representante no Brasil: Instituto de Manejo e Certificação Florestal e Agrícola Imaflora), SGS ICS Certificadora Ltda, Control Union Certifications - Skal International, DNV Business Assurance, BRTÜV Avaliações da Qualidade S.A., todas 
localizadas no estado de São Paulo, GFA Consulting Group, Woodmark - Soil Association, Scientific Certification System, no Paraná.

\subsection{CUSTOS DA CERTIFICAÇÃO}

Durante o processo de certificação, os custos podem ser divididos em diretos e indiretos (CERTIFICAÇÃO..., 2011). Os custos diretos são aqueles que independem das condições em que se encontra a operação candidata ao solicitar o início do processo de certificação e são decorrentes de: avaliações preliminares (auditorias de campo, redação dos relatório, verificação de pré-condicionantes); localização das unidades de manejo; complexidade do sistema de manejo e ambiente sócio-econômico; monitoramento (anual, podendo haver checagens surpresas); taxa anual de certificação (manutenção do sistema de certificação como um todo, variável com o faturamento) e utilização do logotipo FSC, associados à marcação física do produto e catálogos (criação, impressão e distribuição).

Os custos indiretos são aqueles relativos a melhorias no manejo florestal que devem ser feitas para que a operação possa ser certificada. De acordo com Viana et al. (2002) os pontos mais comuns a serem melhorados são: inventários e planejamento da exploração; adequação de máquinas e equipamentos; treinamento e capacitação da mão de obra; adaptação à legislação trabalhista; diversificação no número de espécies utilizadas em manejo de florestas naturais; implantação de sistema de monitoramento; regularização da posse de terra; proteção e recuperação de área de preservação permanente; alterações no sistema de manejo.

Os custos diretos podem ser considerados relativamente altos e variam de acordo com a escala e a intensidade do manejo florestal praticado. Entretanto, esta variação não é proporcional e resulta em um custo maior por unidade de área ou de produção para operações menores. Para evitar que os custos diretos sejam um impedimento à certificação de operações pequenas ou sem capital, várias iniciativas estão sendo realizadas por empresas certificadoras (VIANA et al., 2002).

Um exemplo é a certificação de grupos de áreas florestais que estejam sob a responsabilidade de uma mesma organização (por exemplo, associação ou cooperativa). 
Nesse caso, a avaliação do manejo é feita através de uma amostragem das áreas em questão. Caso o manejo esteja de acordo com os princípios e critérios do FSC, todas as áreas sob a responsabilidade desta organização podem comercializar produtos como certificados e os custos do processo podem ser divididos entre os membros do grupo. Também existem processos simplificados para a certificação de operações florestais de pequena escala e com manejo de baixa intensidade, conhecido como SLIMF (na sigla em inglês, Small and Low Intensity Managed Forest). No Brasil, a certificação SLIMF beneficia principalmente empreendimentos de associações comunitárias, como moradores de Reservas Extrativistas (Resex), projetos de assentamentos (PAE), povos indígenas e quilombolas e pequenas propriedades.

Parte da receita obtida pelo Imaflora na certificação de médias e grandes operações é destinada ao Fundo Social de Certificação, que pode ser solicitado por operações florestais comunitárias ou pequenos proprietários para a realização de avaliações de certificação e atividades afins. Diversas organizações não governamentais e governamentais também apoiam a certificação do manejo florestal desses projetos. $O$ Imaflora ainda possui um Banco de Auditores Voluntários, composto por especialistas de diferentes áreas relacionadas ao manejo florestal, que realizam avaliações de certificação em projetos florestais comunitários a custos mais acessíveis.

\subsection{BENEFÍCIOS DA CERTIFICAÇÃO}

A certificação florestal atinge vários setores da sociedade e traz vantagens tanto pecuniárias, quanto do ponto de vista da conservação ambiental e justiça social. Os principais benefícios da certificação florestal FSC estão apresentadas no Quadro 3.

\begin{tabular}{|c|l|}
\hline Destinatário & \multicolumn{1}{c|}{ Benefícios } \\
Empresário & $\begin{array}{l}\text { Permite o controle do estoque e cria o mercado futuro (o empresário sabe exatamente } \\
\text { quantas árvores, quais espécies possui e quando cada uma estará disponível para a } \\
\text { colheita); aumenta o rendimento da floresta (mais produtividade, menos desperdício e } \\
\text { regeneração mais rápida); vantagem competitiva (agrega valor e otimiza a operação); } \\
\text { facilita o acesso a novos mercados (o selo é um passaporte para novos nichos e } \\
\text { clientes); desenvolve e melhora a imagem pública da empresa; facilidade de acesso a } \\
\text { fontes de financiamento. }\end{array}$ \\
\hline Trabalhadores & Garante o respeito aos direitos legais dos trabalhadores; elimina o trabalho forçado e a \\
\hline
\end{tabular}




\begin{tabular}{|c|l|}
\hline $\begin{array}{c}\text { e habitantes da } \\
\text { floresta }\end{array}$ & $\begin{array}{l}\text { mão de obra infantil; promove os direitos dos povos indígenas e comunidades locais; } \\
\text { contribui para a redução de acidentes de trabalho; cria um novo espaço de participação } \\
\text { para os trabalhadores e povos da floresta na definição dos padrões e no monitoramento } \\
\text { das operações certificadas }\end{array}$ \\
\hline $\begin{array}{c}\text { Sociedade em } \\
\text { geral }\end{array}$ & $\begin{array}{l}\text { Combate a madeira ilegal, garante o recolhimento de impostos e outras contribuições } \\
\text { legais, gerando recursos para o setor público; incentiva o manejo florestal sustentado e } \\
\text { elimina práticas predatórias; mantém as funções ecológicas e a integridade das } \\
\text { florestas; garante o cumprimento às leis vigentes; promove a sustentabilidade do } \\
\text { emprego }\end{array}$ \\
\hline
\end{tabular}

Quadro 3. Benefícios da certificação FSC

Um tema pouco debatido é a interface e as possíveis sinergias entre as políticas públicas e a certificação de produtos florestais. Seria possível, por exemplo, simplificar os procedimentos e reduzir os custos do licenciamento ambiental em unidades de manejo florestal certificadas, pois essas passam por avaliações periódicas com equipes de auditores muito bem qualificados (VIANA ET AL., 2003). Também há a possibilidade de utilizar áreas certificadas como modelo para atividades de extensão florestal, desenvolvendo visitas e treinamentos que podem ser úteis tanto para técnicos quanto para empresários e lideranças políticas ou ainda como pólos de desenvolvimento de tecnologias florestais. As operações certificadas podem ainda oferecer oportunidades para o aprimoramento dos instrumentos atuais de financiamento, ajustando-os à realidade do setor florestal, uma vez que existe uma grande deficiência nos instrumentos voltados para o apoio financeiro e creditício de atividades de produção florestal (VIANA ET AL., 2002)

\subsection{Panorama atual do selo FSC}

Hoje a marca FSC é o selo verde mais reconhecido no setor florestal em todo o mundo, com mais de 600 membros afiliados em 71 países. Em 2007, existiam 906 operações de manejo florestal certificadas, e cerca de 5.400 certificações de cadeia de custódia, distribuídas em mais de 70 países. Foram certificadas 91 milhões de hectares, o que corresponde a $10 \%$ das florestas manejadas do mundo. No Brasil, havia 67 operações florestais com o certificado de manejo florestal enquanto a certificação da cadeia de custódia já foi dada a mais de 340 empresas e comunidades. No país, a área com a certificação FSC corresponde a cerca de 5 milhões de hectares, sendo 
aproximadamente $55 \%$ de florestas nativas e $44 \%$ de florestas plantadas. O país possui o maior numero de empreendimentos certificados na América Latina e é o $6^{\circ}$ no ranking mundial (FSC BRASIL, 2011).

Existem também florestas públicas, como a Floresta Estadual do Antimary, no Acre, e 10 experiências de manejo comunitário certificadas no país, todas localizadas na Amazônia (FSC BRASIL, 2011). Os índios Kayapós da Terra Indígena do Baú, no sudoeste do Pará, até 2008, detinham o único certificado FSC para produtos indígenas no Brasil. Responsáveis pelo manejo de 1,5 milhões de hectares de floresta, a maior área certificada em florestas tropicais do mundo, os Kayapós produziram cerca de quatro toneladas de óleo de castanha-do-Brasil certificado em 2007.

Cerca de $40 \%$ da área certificada no Brasil está nas plantações florestais localizadas majoritariamente no sul e sudeste do país, principalmente na Mata Atlântica. Outros 30\% estão nas mãos de comunidades tradicionais, destacando-se a Terra Indígena do Baú, com mais de 1,5 milhão de hectares, certificada para o manejo de produtos florestais não-madeireiros. Outros $23 \%$ estão certificados para a produção de madeira em escala empresarial, e 9\% das áreas são plantações florestais na Amazônia, concentradas nos estados do Pará, Amapá e Mato Grosso. Áreas manejadas por comunidades para a extração de madeira constituem menos de $1 \%$ do total de áreas florestais brasileiras certificadas (HowStuffWorks, 2011).

Já existem mais de 200 tipos de produtos com o selo FSC no Brasil, disponíveis nas principais lojas de varejo. São variados os setores que hoje fazem uso do selo FSC, incluindo o setor de casa e decoração, construção civil, cosmético, móveis, livros, utensílios domésticos, entre outros (FSC BRASIL, 2011).

\section{CONSIDERAÇÕES FINAIS}

O selo FSC nasceu como fruto de iniciativas que buscavam a sustentabilidade do desenvolvimento no mundo inteiro, sendo esse um compromisso assumido por diversos países. O setor florestal reconheceu a necessidade de se adequar a esse novo momento e aderiu à certificação como um instrumento para assegurar a origem dos seus produtos e, nesse contexto, a certificação FSC é a que se destaca dentre as demais. O selo FSC 
não só atende às exigências de um mercado consumidor consciente, como também desempenha importante papel na promoção de um desenvolvimento sustentável por manter padrões de desempenho ambiental, social e econômico para as operações de manejo no mundo inteiro.

A caminhada rumo ao manejo florestal sustentável é longa e, enquanto ela é percorrida, práticas de gestão para um bom manejo florestal devem ser utilizadas ao mesmo tempo em que a pesquisa e o esforço para o melhoramento contínuo são estimulados. Nesse contexto, a certificação florestal parece ser um instrumento capaz de possibilitar o alcance do objetivo final.

\section{AGRADECIMENTOS}

Ao Núcleo de Estudos em Pesquisa e Planejamento Ambiental (NEPPA) da Universidade Federal de Lavras (UFLA) pelo apoio técnico-científico e ao CNPq, FAPEMIG e CAPES pelo apoio financeiro.

\section{REFERÊNCIAS}

BORGES, L. A. C. A legislação como premissa da política e da gestão ambiental. 2005. 290p. Dissertação (Mestrado em Engenharia Florestal) - Universidade Federal de Lavras, Lavras, 2005.

CERTIFICAÇÃO FLORESTAL. Padrões Nacionais de Manejo Florestal. Disponível em: http://www.fsc.org.br/index.cfm?fuseaction=conteudo\&IDsecao=175. Acesso em: 12 . Out. 2011;

FSC BRASIL. Conselho Brasileiro de Manejo Florestal - Certificação Florestal.

Disponível em: http://www.fsc.org.br/index.cfm?fuseaction=conteudo\&IDsecao=74.

Acesso em: 13 out. 2011.

GUÉRON, A. L. Rotulagem e certificação ambiental: uma base para subsidiar a análise da certificação florestal no Brasil. 2003. 109p. Dissertação (Mestrado em Ciências em Planejamento Energético) - Universidade Federal do Rio de Janeiro, Rio de Janeiro, 2003. 
RELATÓRIO BRUNDTLAND, Nosso Futuro Comum. 2 ed., Rio de Janeiro, Fundação Getúlio Vargas, 1991.

SOUSA, A. C. A. A evolução da política ambiental no Brasil do século XX. Revista Achegas, Rio de Janeiro, n. 26, nov/dez, 2005.

UNITED NATIONS CONFERENCE ON THE HUMAN ENVIRONMENT. 5-16 de jun. 1972, Estocolmo, Suécia. Declaration of the United Nations Conference on the Human

Environment, Stockholm. United Nations Environment Programme, 21st plenary meeting, Chapter 11. 16 jun. 1972. Disponível em:

http://www.unep.org/Documents.Multilingual/Default.asp?documentid=97\&articleid=1503. Acesso em: 04 out. 2011.

QUEIROZ, D. Certificação ambiental. 2003. 49p. Monografia (Graduação em Engenharia Florestal) Universidade Federal de Lavras, Lavras.

VIANA, E. C.; CARVALHO, A. M. M. R.; OLIVEIRA, P. R. S.; VALVERDE, S. R.; SOARES, T. S. Análise técnico-jurídica do licenciamento ambiental e sua Interface com a certificação ambiental. Revista Árvore, Viçosa-MG, v.27, n.4, p.587-595, 2003.

VIANA, V. M.; FREITAS, A. G.; CAFFER, M. M.; FILHO, W. S; ARMELIN, M. J. C. Certificação florestal. In: Cadernos da Reserva da Biosfera da Mata Atlântica: série políticas públicas, 23. SIMÕES, L. L. (org.). São Paulo: Conselho Nacional da Reserva da Biosfera da Mata Atlântica, 2002. 98 p. Disponível em:

http://www.rbma.org.br/rbma/pdf/Caderno 23.pdf. Acesso em: 13 out. 2011.

HOWSTUFFWORKS - Como funciona a certificação florestal FSC. Publicado em 13 de outubro de 2008 (atualizado em 21 de outubro de 2008). Disponível em: http://ambiente.hsw.uol.com.br/fsc3.htm. Acesso em: 13 out. 2011

VIOLA, E. O movimento ecológico no Brasil (1974-1986): do ambientalismo à ecopolítica. Revista Brasileira de Ciências Sociais, São Paulo, v.1, n.3. 1987. Disponível em: http://www.anpocs.org.br/portal/publicacoes/rbcs $00 \quad 03 /$ rbcs03 01 .htm. Acesso em: 23 set. 2011. 